\title{
Green Bonds: Between economic incentives and eco-change
}

\author{
Răzvan HOINARU \\ Member of the Club of Rome (EU Chapter) \\ Queen Mary University of London, United Kingdom \\ r.hoinaru@qmul.ac.uk \\ Cedine BENSON \\ Johannes Gutenberg University of OMainz, Germany \\ cbenson@students.uni-mainz.de \\ Georgiana Oana STĂNIL $\breve{A}$ \\ Bucharest University of Economic Studies, Bucharest, Romania \\ oana.stanila@ase.ro \\ Florin DOBRE \\ Bucharest University of Economic Studies, Bucharest, Romania \\ florin.dobre@cig.ase.ro \\ Daniel BUDA \\ Babeș- Bolyai University, Cluj- Napoca, Romania \\ daniel.buda@fspac.ro
}

\begin{abstract}
As the investor base committed to financing sustainable companies in an attempt to combat the climate crisis expands, green financial products have become more attractive to issuers, corporate and sovereign alike. As a result, the EU is attempting to create favourable market conditions which mobilise the allocation of private capital for investments that reduce the contribution to climate change. As part of the EU Commission's Action Plan for Sustainable Finance, it intends to create Green Bond Standards which aim to support the transition to greener securities investments. As a foundation, we provide an overview of the green bond market development. We then consider investment challenges such as incentivisation and transparency and discuss whether the Green Bond Standards shall likely resolve these issues. Furthermore, we confer that enforceability of current green securities regulations is weak to non-existent and propose possible policy approaches which address these issues.
\end{abstract}

Keywords: green bonds, EU Commission, sustainable finance, climate change.

\section{Introduction}

As the investor base committed to financing sustainable companies in an attempt to combat the climate crisis expands, green financial products have become more attractive to issuers, corporate and sovereign alike. As a result, green bond issuances increased drastically from 3 $\%$ of total global bond issuances to $4.5 \%$ in just a year. In light of the rapidly growing green bond market, the Commission has incorporated creating an EU Green Bond Standard as part of its Action Plan on Financing Sustainable Growth. (Financial Stability, Financial Services and Capital Markets Union, 2018) The Commission has recognised the need for frameworks at the EU level and intends to create a global best practices benchmark which will create stability in the green bond markets by harmonising definitions of green projects as well as prescribing enhanced transparency. The Green Bond Standards shall build on current market practices, such as the ICMA Green Bond Principles.

This paper takes into consideration green bonds in all of their three forms: sovereign, sub-sovereign (municipal bonds) and corporate. In the first section of this paper, we provide an overview of key market developments as well as recognised types of green bonds. In the 
second section, we offer data analysis on the current state of the market and discuss whether conditions are favourable for green securities. Furthermore, we aim to present the similarities and differences between corporate green bonds and sovereign green bonds to better understand the competition between green bond issuers. In the third section, we establish the connection to current negotiations of the EU Green Bond Principles and present notable findings of the TEG Report. In the fifth section, we discuss issuer incentives based on analytic data which seem to suggest not only a better performance of green-certified securities, but also overall asset performance (Busu, Vargas and Gherasim, 2020). Finally, in section six, we draw attention to adversities in the fragile balance between bondholder protection (Tantau \& Gavrilescu, 2019) and issuer interest and discuss possible solutions which may be addressed by the upcoming EU Green Bond Standards.

\section{Defining Green Finance: Key Developments in the Green Bond Market}

In 2007, the European Investment Bank coined and issued the Global Awareness Bond to raise money and finance one hundred and sixty energy efficiency projects, listed on Luxembourg Stock Exchange (LuxSE). (European Investment Bank, 2018) (Nyamongo, 2017) This spark generated positive responses from SEB (Sandinaviska Enskilda Banken AB) and the World Bank, which by connecting the dots of funding, energy needs, agriculture, clean transportation, water and waste management issued the first so-named 'Green Bond' in 2008. (The World Bank, 2019) In short, a green bond (or climate bond) refers to a type of ordinary bond which is issued by a company for use in climate and environmental projects such as pollution-free transport, sustainable technologies, energy efficiency, etc. Typically, these types of bonds are guaranteed by the company's assets and are supported by the issuer's balance sheet. Furthermore, green bonds are usually subject to tax benefits for issuers and investors, such as tax exemptions and tax credits, making them a more attractive investment option compared to traditional bonds.

Standardisation attempts commenced in 2014, when the Green Bond Principles (GBP) were published by several banks, subsequently supported by the International Capital Market Association (ICMA) and adopted by the vast majority of market participants (EU Technical Expert Group on Sustainable Finance, 2019). The aforementioned recommended principles were further developed by the ICMA in 2018, to ensure integrity and transparency in sustainable investments as well as supporting investors' activism in shaping the development of the environmental impact of their green bond investment. Concentrated on transparency, accuracy, and integrity in the issuers - stakeholders' process, the Green Bond Principles, as they are described in the 2018 ICMA's paper, are based on four main aspects: a) the use of proceeds, b) the importance of evaluation and selection of the projects, c) proceeds' management, d) the phase of reporting. (International Capital Market Association, 2018)

From the ICMA perspective, there are four types of green bonds:

-Standard Green Use of Proceeds Bond: represents a standard recourse-to-the-issuer debt obligation aligned with the GBP;

-Green Revenue Bond: a non-recourse-to-the-issuer debt obligation aligned with the GBP (the credit exposure in the bond is to the pledged cash flows of the revenue streams, fees, taxes, and whose use of proceeds go to related or unrelated green projects);

-Green Project Bond: used for single or multiple green projects for which the investor has direct exposure to the risk of the project(s) with or without potential recourse to the issuer, and that is aligned with the GBP;

-Green Securitised Bond: a bond collateralised by one or more specific green projects, including but not limited to covered bonds, ABS, MBS, and other structures; and aligned with the GBP. The first source of repayment is generally the cash flows of the assets. 
In addition, these principles contain several recommendations, including the one to obtain an external review and the one for the issuer to explain the green bond's alignment with the issuer's overall strategy. (International Capital Market Association, 2018)

\section{The Global Green Bond Market}

\section{State of the Market}

Applying the GBP generates a balanced, transparent and competitive worldwide green bond market. A major highlight in the evolution of the green bond market was the recognition of green bonds in 2011 by G20, IMF and OECD, and the World Bank symposium of green bonds. Shortly after the first corporate and sub-municipal bonds were issued. At the recent COP 21 Paris, social bonds principles were created followed by sustainability bonds principles. (Filkova, Monica; Frandon-Martinez, Camille; Giorgi, Amanda;CFA, 2019) Since 2008 , the cumulative value of Green bonds amounts to $\$ 521 \mathrm{bn}$, out of which green bonds in the total value of $\$ 200$ bn were issued in 2019 alone. (Filkova, Monica; Frandon-Martinez, Camille; Giorgi, Amanda;CFA, 2019)

According to a Climate Bonds Initiative (CBI) report (Filkova, Monica; FrandonMartinez, Camille; Giorgi, Amanda;CFA, 2019), Fannie Mae, an Asset Back security in the USA is the biggest green bond issuer in the world, holding USD 20.1bn in green bonds, followed by the Industrial Bank of China and the French Government. Interestingly, even the German government is the fourth biggest market share owner (with 5\%) with the Government of Belgium taking fifth place followed by Ireland. (Filkova, Monica; Frandon-Martinez, Camille; Giorgi, Amanda;CFA, 2019) It is interesting to notice that the main issuers of green bonds in 2019 still remained the USA, but France took second place, outrunning China. (Filkova, Monica; Frandon-Martinez, Camille; Giorgi, Amanda;CFA, 2019) Although sovereign green bonds make up the majority of the green bond market, the issuances of corporate green bonds has been growing and currently constitutes over $46 \%$ of the market compared to $37 \%$ in 2018 .

It also worth noting that more than half of green bond proceeds were earmarked in 2018 for energy projects followed by investments in law-carbon buildings and clean transport. It is necessary to highlight that, in the case of sovereign green bonds, the energy sector had the same importance as the transport sector and the land use.

\section{Sovereign Green Bonds}

Sovereign green bonds are issued by national governments and can be denominated in local currency or foreign currency (for example Euros, Dollars, Pounds). As researchers show, 2017 was considered 'the year of the sovereign green bond', marked by Poland's sovereign market opening in the late 2016, followed by France, Belgium and Ireland. (Bloomberg Quicktake, 2019) According to the Climate Bonds Initiative Publication, Sovereign Green Bond Briefing (Giuliani \& Sonerud, 2018), there are seven steps to issuing a sovereign green bond:

-Engaging governmental stakeholders;

-Establishing a green bond framework;

-Identifying eligible green budget items;

-Arranging an independent review;

-Issuing the green bond;

-Monitoring and reporting;

-Repeat.

Supporting green finance by issuing sovereign green bonds could be considered the equivalent to the state's orientation towards long-term green growth strategies, increasing reputational benefits, reinforcing the climate change agenda or sustainability policies, which 
could in turn attract new environmentally friendly investors and generate a boost of national green hubs. For example, Poland experienced significant investor diversification, with green investors making up $61 \%$ of the investor pool, almost none of which had previously invested in sovereign bonds from Poland. (institutionalinvestor.com, 2017)

By investing in resilient green projects through green bonds, governments may become a model for the private sector in the process of improving the investment policy in green assets. In the context of upcoming years, when public funds will not be enough to cover the climate change challenges or the infrastructure's demands (The new climate economy, 2014), it is essential to mobilise investors' private capital towards climate resilient investments. From this perspective, it is important for the governments to concentrate on the synergies between green projects and the private sector's demands as well as possible policies of tax reliefs or subsidies for private investments in green priority sectors.

Furthermore, municipalities and cities have developed a sub-national green bond in the public domain (also called 'green muni bonds'), representing loans that investors make to local governments. The issuers consist of a variety of sub-national representatives, such as cities, provinces or government agencies. Green muni bonds tend to have a longer maturity (11.8 years) and a higher credit rating than ordinary muni bonds. It is worth mentioning that the market has increased between 2011 to 2017, year reaching $\$ 11,2 \mathrm{~B}$, representing 2, $6 \%$ of the overall sub-national bonds market. (Flammer, Green Bonds: Effectiveness and implications for public policy, 2019) According to recent data, between January 1, 2010 and December 31, 2018 out of 1,224,774 issued ordinary muni bonds, 4,794 were green. (Flammer, Green Bonds: Effectiveness and implications for public policy, 2019)

More specifically (Giuliani \& Sonerud, 2018):

-In the US, states and municipalities have issued USD18.5 billion worth of green bonds, accounting for $60 \%$ of sub-sovereign issuance globally;

-European sub-sovereigns are responsible for $30 \%$ of the global sub-sovereign market (USD8.8bn issued), followed by Canada (USD2.1bn) and Australia (USD962m);

-Sub-sovereigns in Australia, Canada and the US have issued green bonds financing renewable energy, energy efficiency, low-carbon public transport, and sustainable land use.

After analysing the role of the sovereign green bonds, we can conclude that a strong national policy of issuing green bonds could contribute to the national governmental policies and actions on climate change, sustainability, green growth, resilient economy, as targeted in the Paris Agreement.

\section{Corporate Green Bonds}

Another recent developed category of climate bond is represented by corporate green bonds, issued by financial and non-financial corporations, which choose to offer funding for projects that follow their environmentally objectives. This usually includes the use of renewable energy and energy efficiency measures in their operations.

Chronologically worth noting is that Unilever issued the first corporate green bond to improve the efficiency of the water and energy in the internal processes of the company, totalling $£ 250 \mathrm{~m}$, followed by other companies including Apple in 2016 (value 1.5 bn USD) and in 2017 (value 1 bn USD), PepsiCo, Inc., Verizon, and Vodafone. (Global Green Bond Partnership) Apple issued its first green bond to finance clean energy projects for its overall business processes and operations, putting emphasis on the use of renewable energy and increasing energy efficiency. Regarding its second green bond, Apple representatives of management emphasised that 'leadership from the business community is essential to address the threat of climate change and protect our shared planet'. (Forbes, 2017)

Despite the increase of green securities, the total issuance of corporate climate bonds represents a small part of the bond market, which is estimated at $\$ 92.18$ trillion in 2016 . (SIFMA Research Department, 2017) 
Corporate green bonds seem to be more popular in Europe, (especially in France, followed by Netherlands, Germany and Italy) than in Asia or the USA. (Flammer, Corporate Green Bonds, 2018)

The numbers may look high, however, when compared to sovereign bond market the corporate bond market is rather new, small and as a result, we cannot yet estimates its 'effectiveness in terms of financial and environmental performance, and the implications for firm-level outcomes'. (Flammer, Green Bonds: Effectiveness and implications for public policy, 2019)

However, the research over the past years regarding the market of corporate green bonds reflects the efficiency of these bonds both for the expenditure of the companies' green projects and their commitment to the environment and also for the firms' financial performance. It is considered that corporate green bonds attract investors, creating a broad base of interested actors aimed to invest in these types of bonds; a match between these considerations reveals the importance that corporate green bonds have for the companies, but also for the environment. (Flammer, Green Bonds: Effectiveness and implications for public policy, 2019) At least from the perspective of the elements analysed so far in specialised literature which itself is not yet substantially developed.

\section{Notable Findings of the TEG Report}

Based on extensive research regarding green bond and green bond market development within the past few years, it can be concluded that standards and expectations on the green bond markets vary, depending on jurisdictions, economic sectors or the dimension of the issuers, but also on the overall accessibility of the worlds' bond markets. (EU Technical Expert Group, 2019, p. 18) Besides the application of the principles above, the importance of identifying and establishing a harmonised guiding framework for the green bonds market at least at the European level is of major interest. As we analyse in this section, the ICMA Green Bond Principles were the first step to combatting greenwashing as well as facilitating transactions in the green securities market thus, making them an essential foundation for the EU Green Bond Standards. In June 2018, the European Commission created a Technical Expert Group on sustainable finance (TEG) and tasked it to develop the following: 1) a unified classification system for sustainable economic activities, 2) an EU Green Bond Standard, 3) benchmarks for low-carbon investment strategies, and 4) guidance to improve corporate disclosure of climate-related information. (EU Technical Expert Group, 2019, p. 8) The TEG continued its work on providing the foundation for an EU Green Bond Standard and published its report in 2019.

The TEG Report concentrates on the green bond market development, reaction, and evolution, launching fundamental recommendations; according to TEG Report, for a safe, efficient, transparent and trustful EU green bond market, it is necessary to create at least a voluntary standard (EU Green Bond Standard - GBS) as a way to encourage interested actors to issue green bonds as well as raise the investors' interest to find in green bonds a solution for profitable green projects. As a result, the TEG has highlighted ten recommendations, concentrating on the alignment with EU-taxonomy, the establishment of a voluntary Green Bond Framework and also the creation of mandatory rules for reporting and verification. In short, establishing a set of European standards could diminish the uncertainty on the current green bond market (by linking the objectives of the green projects with the EU Taxonomy), creating a transparent and safer market through certain verification and reporting criteria and offering an official EU standard for this emerging market. Furthermore, this could motivate Member States to better uphold the objectives of the Paris Agreement. Moreover, the European framework may serve as a model for other countries and could also offer a variety of opportunities to implement incentives for issuers and investors. 
There are many differences between the vision of the EU Green Bond Standard and the Green Bond Principles. First, regarding the use of proceeds, this remains a recommendation within the Green Bond Principles, but in the proposed standards, this is meant to be a requirement. The EU standards shall require the use of proceeds in legal documentation, either in the Base Prospectus or in the Final Terms. (EU Technical Expert Group, 2019, p. 8) Regarding the importance of evaluation and selection of the projects, this may raise a wider discussion; from the perspective of eligibility criteria, the GBP recommend a substantial contribution to environmental objectives and also strong social safeguards which especially focus on informing the investors about the potential risks of the projects (material, environmental and social). On the other hand, the proposed GBS involve wider criteria on this topic, especially based on the alignment with the EU Taxonomy and with the eight fundamental conventions identified in the International Labour Organisation's Declaration on Fundamental Rights and Principles at Work. Every eligible project should include the following requirements: (1) substantial contribution to environmental objectives, (2) do-nosignificant harm (3) minimum social safeguards; (4) technical screening criteria. (EU Technical Expert Group, 2019, p. 8) What is interesting to notice is that the GBS concentrates on criteria such as 'do-no-significant harm' (referring to the EU Taxonomy's Environmental Objectives) and 'technical screening criteria', which are not considered in the GBP. In the field of proceeds management, the GBP only recommend disclosure of the proportion of proceeds used for refinancing, whereas the GBS require it (as 'specific technical requirements'). The TEG makes similar recommendations regarding the procedure of impact monitoring and reporting, as well as external review: the GBP recommend it, while the GBS required it. Furthermore, while the accreditation of external reviewers is not addressed in the GBP, the GBS make it a subject of a centralised scheme, operated by the European Securities and Markets Authority (ESMA).

The most stringent and urgent problem, however, seems to be the overall need of a new global policy and a new business model to accommodate green bonds. It is true that, in practice, the international green bond market works well for now - as we can see in the section below, but it could be improved by new standards and a legal framework, which could contribute to enhancing trust for both investors and issuers (especially corporates). Furthermore, offering a legal framework and a high level of transparency and trust may raise the interest for more innovative green projects financed on the market. We appreciate that a first step in the process of creating a worldwide legal framework should necessarily involve an international standardization of what green bond means and, besides this, an improved way of reporting; not eventually, it is essential to pay attention to disclosure: both pre-issuance and post-issuance transparency is fundamental. An adequate framework may increase the role that green bonds have for reaching the objectives of the Paris Agreement.

\section{Incentives}

Implementing qualifying green standards for securities seems to be a large step in making green bonds more attractive to investors motivated by sustainability goals. The Green Bond Standards will ideally provide investors with quality assurance and transparency. Green bonds may be made more attractive to issuers as well as investors if they qualify for monetary benefits, usually in the form of tax benefits. Apart from general tax incentives, newer studies have shown that the effects of green bond issuance may also provide incentives for issuers. Such financial instruments stopped being esoteric and are increasingly more of a mainstream presence, especially as certain Directives such as UCIT and Capital Requirements Regulation provided some protection to market participants. (Doran \& Tanner, 2019)

The financial characteristics of 'green' and 'bond' matched together plus the correlation the green bonds market has to the stock market already provide good premises for investors. An entire supply and demand chain of green financing started to exist along with 
systemic action, technological change and a higher expectation of future profitability. (Zhou \& Cui, 2019) Studies show that both ROA and ROE are likely to increase in a longer period of time, implying a performance increase of even $11 \%$ and of $0.7 \%$ on the stock of certified green bonds (e.g. ICMA GBP). (Flammer, Green Bonds: Effectiveness and implications for public policy, 2019) However, the situation was not always like this as between 2013 to 2017, estimates derived from a matching method followed by a two-step regression showed a negative yield of $0.02 \%$.

Therefore, the incentives to invest in green bonds are not only driven by economic motives like investor demand, which is still primordial. The cost-benefit analysis implies higher political and legal protection of the investment and improved environmental action. Green bonds are also thought to influence CO2-reduction, reducing emissions with 21.6 tons of $\mathrm{CO} 2$ per $\$ 1 \mathrm{M}$ of assets. (Baker, et al., 2020) Research showed that investors are pleased with less profit if the investment contributes to sustainability. They can eventually capitalise indirectly on marketing themselves as a greener company and disclose better data in their non-financial reporting data, indirectly attracting attention, sales, investments, human capital, etc.

That being said, issuing a green bond alone is not feasible enough to incentivise issuers to move to greener projects as opposed to financing the project with a standard bond. In contrast to the ICMA Green Bond Principles, the Green Bond Standards shall prescribe higher disclosure obligations, a more rigorous qualification process and continuous monitoring in order to safeguard investments from greenwashing. This shall likely, as a result, impose higher costs upon issuers as well as less flexibility in fund usage after issuance. The EU taxonomy aims to provide financial benefits to sustainable companies which must be seen in the same context, as these will be relevant, in order to ensure that compliance with the Green Bond Standards still remains attractive to market actors. This is only promising if issuing a green bond for the project is more attractive to market participants compared to standard bond issuances. It is yet to be seen how exactly the Commission intends to provide incentives to support cultivating the growth of the green financial market.

\section{Creditor Protection}

Although the ICMA's Green Bond Principles are a significant step forward in global harmonisation and combatting greenwashing, upholding the standards set by the Green Bond Principles is neither mandatory nor legally enforceable: „The Green Bond Principles are voluntary process guidelines that neither constitute an offer to purchase or sell securities nor constitute specific advice of whatever form (tax, legal, environmental, accounting or regulatory) in respect of Green Bonds or any other securities. The Green Bond Principles do not create any rights in, or liability to, any person, public or private”. (ICMA, 2018)

Not only must issuers be incentivised to comply with Green Bond Standards, investors must be incentivised to invest in EU-certified green securities. A central issue the green bond markets face today is the lack of transparency and inferred risk of greenwashing, which can be attributed to the fact that pre- and post-issuance reporting is often merely "recommended" and non-compliance with qualification conditions is practically not enforceable. This rattles investors' trust at the cost of companies which have true intentions and seek to contribute to sustainable development. Higher creditor protection may be achieved by mandating practices which enhance transparency as well as establishing a regulatory foundation which supports increased contractual rights.

\section{Transparency under the TEG Report}

The proposed draft of the Green Bond Standards by the TEG foresees inclusion of the Green Use of Proceeds to be specified in the legal documentation. (EU Technical Expert Group, 2019 , p. 59) The proposed Standards require the issuer to include pre-issuance disclosure of 
green use of proceeds as well as continuous post-issuance allocation and impact reporting in the Green Bond Framework.

The TEG suggests requiring the publication of the Green Bond Framework on the issuer's website or other communication channel, before or at the time of the bond issuance. Furthermore, the TEG strongly advises the Commission to incorporate mandatory and continuous impact monitoring and reporting. (EU Technical Expert Group, 2019, p. 60) In addition, not only should the green use of proceeds be disclosed in the Green Bond Framework, the disclosure of proportions of proceeds used for refinancing should be required under the Green Bond Standards. The mandatory nature of the reporting and disclosure standards is a welcome improvement to the Green Bond Principles' recommended reporting practice. (EU Technical Expert Group, 2019) This does however put pressure on the EU to have precise specifications regarding which projects are considered green and which disclosure and reporting obligations apply to each. However, this in turn shall enhance transparency for market actors and create a hallmark of quality for EU-certified issuers.

\section{Enforceability}

A central issue which seems to be subject to avoidance are private enforcement rights of green bond holders. As discussed above, green finance investors are highly motivated by factors other than possible profit, namely supporting sustainable development and the transition to environmental practices. In turn, studies conclude that green investors are satisfied with lower premiums to the benefit of the issuer. It is therefore crucial that the nonfinancial interests of the investor be protected and where possible, enforceable.

This issue seems to have been recognised by the TEG and they have, as a result, recommended mandatory incorporation of the green use of proceeds in the legal documentation, i.e. the Green Bond Framework (such as in the Base Prospectus or the Final Terms) under the EU Green Bond Standards. However, it must be noted that green bonds which are based on the use of proceeds concept do not directly fund green projects (which would be green project bonds). The funds raised are designated for green projects, however flow to the entire balance sheet of the issuer and in turn finance all of the issuer's projects. The proceeds may therefore be used to finance the issuer's brown investments and thus collide with the investor's initial intentions and values. Though green use of proceeds bonds cannot necessarily be seen as ineffective, there is risk that the projects financed my not be aligned with the goals of the Paris Agreement.

The TEG has attempted to address this issue by recommending standards which enhance transparency; however, the report makes no recommendations regarding noncompliance. In practice, green bond issuers usually do not voluntarily infer actionable rights on bondholders in the event that the proceeds aren't used in the specified manner. In fact, they include covenants directly into the bond terms and conditions which exculpate them from any liability if the issuer were to fail to use the proceeds in the specified manner or comply with reporting obligations. This may have drastic effects, as it allows space for abuse of the "green label" and compromise the level of quality and integrity expected by investors. Striking a balance between investor protection and attractiveness to issuers while not compromising the feasibility of such green financial products has proved to be a highly tedious and precarious undertaking. Nevertheless, requiring issuers to provide at least some actionable rights to the investor may provide a solution without imposing off-putting constraints. The Green Bond Standards or other applicable regulations within the taxonomy may introduce monetary penalties imposed by oversight authorities if infringements occur. Furthermore, in order to relieve administration authorities, requiring a minimum standard of actionable rights in the legal documentation so that investors may assert claims before the civil courts would allow for investor assurance as well as flexibility, as the specifications of the provisions shall still be negotiated inter parts. For example, the Standards could require that failure to allocate the 
funds to Green Projects constitutes an event of default. The issuer may, for example, incorporate conditions under which the funds may be used to finance other sustainable projects in the event that not all funds were needed, or the project was terminated without factually undermining the investors' financial motivations.

\section{Conclusion}

The rapid growth of investor interest in green financial instruments has invoked the need to create conditions in the financial markets which are favourable for green investments. On the basis of current analysis, we have discussed how the EU Green Bond Standards may benefit the transition to greener securities. Although the green securities market may still only be seen as an emerging market, its growth and impact within less than a decade has been exponential. Furthermore, we have deliberated which issues may still arise and should be taken into consideration by policy makers. We have found that the main issue with the TEG recommendations is that the report makes no recommendations regarding non-compliance. Whether Member States shall be encouraged to implement their own non-compliance sanctions, or the Green Bond Standards shall remain factually non-enforceable is yet to be determined. Nevertheless, the need for a homogenous framework which guarantees quality and transparency is imperative.

\section{References}

Baker, S. E., Stolaroff, J. K., Peridas, G., Pang, S. H., Goldstein, H. M., Lucci, F. R., . . . McCormick, C. (January 2020). Getting to Neutral: Options for negative carbon emissions in California. Von https://www-gs.llnl.gov: https://wwwgs.llnl.gov/content/assets/docs/energy/Getting to Neutral.pdf abgerufen

Bloomberg Quicktake. (24. March 2019). What are green bonds and how 'green' is green? Von bloomberg.com: https://www.bloomberg.com/professional/blog/green-bonds-greengreen/ abgerufen

Busu, M., Vargas, M.V., Gherasim, I.A. (2020), "An analysis of the economic performances of the retail companies in Romania", Management \& Marketing. Challenges for the Knowledge Society, Vol. 15, No. 1, pp. 125-133, DOI: 10.2478/mmcks-2020-0008.

Chestney, N. (23. October 2019). Green bond issuance surpasses $\$ 200$ bln so far this year. Von reuters.com: https://www.reuters.com/article/us-greenbonds-issuance/green-bondissuance-surpasses-200-bln-so-far-this-year-idUSKBN1X21L1 abgerufen

Doran, M., \& Tanner, J. (23. September 2019). Critical challenges facing the green bond market. Von iflr.com: https://www.iflr.com/article/b1lmxbv3f6b5td/critical-challengesfacing-the-green-bond-market abgerufen

Ekblom, J. (5. December 2019). Green bonds set for shake up as EU agrees rules for sustainable financial products. Von reuters.com: https://www.reuters.com/article/us-eu-financeclimate/green-bonds-set-for-shake-up-as-eu-agrees-rules-for-sustainable-financialproducts-idUSKBN1Y9251 abgerufen

EU Technical Expert Group. (2019). Report on EU Green bond standard. ec.europa.eu. Von https://ec.europa.eu/info/sites/info/files/business_economy_euro/banking_and_finance/d ocuments/190618-sustainable-finance-teg-report-green-bond-standard_en.pdf äbgerufen

European Investment Bank. (22. January 2018). 10 years of Green Bonds: Join the celebration. Von eib.org: https://www.eib.org/en/infocentre/ten-years-of-green-bonds.htm abgerufen

Filkova, Monica; Frandon-Martinez, Camille; Giorgi, Amanda;CFA. (March 2019). Green

Bonds: The state of the market 2018. Von icmagroup.org: https://www.icmagroup.org/assets/documents/Regulatory/Green-Bonds/Public-researchresources/CBIGBMFina1032019-120319.pdf abgerufen

Financial Stability, Financial Services and Capital Markets Union. (8. March 2018). Commission action plan on financing sustainable growth. Von ec.europa.eu: https://ec.europa.eu/info/publications/180308-action-plan-sustainable-growth_en abgerufen

Flammer, C. (November 2018). Corporate Green Bonds. Von bu.edu: https://www.bu.edu/gdp/files/2018/11/GEGI-GDP.WP_.Corporate-Green-Bonds.pdf abgerufen

DOI: 10.2478/picbe-2020-0022, pp. 236-245, ISSN 2558-9652| Proceedings of the $14^{\text {th }}$ International Conference on Business 
Flammer, C. (June 2019). Green Bonds: Effectiveness and implications for public policy. Von nber.org: https://www.nber.org/papers/w25950.pdf abgerufen

Giugale, M. (10. October 2018). The Pros and Cons of Green Bonds. Von worldbank.org: https://www.worldbank.org/en/news/opinion/2018/10/10/the-pros-and-cons-of-greenbonds abgerufen

Giuliani, D., \& Sonerud, B. (2018). Sovereign green bonds briefing. Climate Bonds Initiative.

Global Green Bond Partnership. (kein Datum). Green Bond Roadmap. Von globalgreenbondpartnership.org: https://www.globalgreenbondpartnership.org/types-ofgreen-bonds abgerufen

Hirtenstein, A., \& Husband, S. (9. October 2018). Security That Triggered a Recession Reworked to Green the Earth. Von bloomberg.com: https://www.bloomberg.com/news/articles/2018-10-09/security-that-triggered-arecession-reworked-to-green-the-earth abgerufen

ICMA. (June 2018). Green Bond Principles-Voluntary Process Guidelines for Issuing Green Bonds. Von icmagroup.org:

https://www.icmagroup.org/assets/documents/Regulatory/Green-Bonds/Green-BondsPrinciples-June-2018-270520.pdf abgerufen

institutionalinvestor.com. (3. April 2017). A Greener Hue to European Sovereigns. Von institutionalinvestor.com:

https://www.institutionalinvestor.com/article/b1505p5mkwcs31/a-greener-hue-toeuropean-sovereigns abgerufen

International Capital Market Association. (June 2018). Green Bond Principles (GBP). Von icmagroup.org: https://www.icmagroup.org/green-social-and-sustainabilitybonds/green-bond-principles-gbp/abgerufen

morganstanley.com. (11. October 2017). Behind the Green Bond Boom. Von morganstanley.com: https://www.morganstanley.com/ideas/green-bond-boom abgerufen

Nyamongo, L. (25. May 2017). Green Bonds 102: A Brief History of Green Bonds. Von medium.com: https://medium.com/@lillianyamongo/green-bonds-102-a-brief-historyof-green-bonds-a6b806bcc86c abgerufen

Polkuamdee, N. (23. November 2019). Over 10 firms to launch green bonds next year. Von bangkokpost.com: https://www.bangkokpost.com/business/1800359/over-10-firms-tolaunch-green-bonds-next-year abgerufen

Rajwanshi, Y. (26. November 2019). Are Green Bonds as Good as They Sound? Von Berkley Economic Review: https://econreview.berkeley.edu/are-green-bonds-as-good-as-theysound/ abgerufen

Razzouk, A. (6. March 2018). Green bonds do more harm than good. Von eco-business.com: https://www.eco-business.com/opinion/green-bonds-do-more-harm-than-good/ abgerufen

SIFMA Research Department. (2017). SIFMA 2017 Fact Book. New York. Von https://www.lexissecuritiesmosaic.com/gateway/sec/public-statements/10_US-FactBook-2017-SIFMA.pdf abgerufen

Tantau, A., Gavrilescu, I., (2019), "Key anxiety factors for buying an electric vehicle", Management \& Marketing. Challenges for the Knowledge Society, Vol. 14, No. 2, pp. 240-248, DOI: 10.2478/mmcks-2019-0017.

The new climate economy. (2014). Better Growth,Better Climate. https://newclimateeconomy.report/2014/.

The World Bank. (18. March 2019). 10 Years of Green Bonds: Creating the Blueprint for Sustainability Across Capital Markets. Von worldbank.org: https:/www.worldbank.org/en/news/immersive-story/2019/03/18/10-years-of-greenbonds-creating-the-blueprint-for-sustainability-across-capital-markets abgerufen

Zhou, X., \& Cui, Y. (3. December 2019). Green Bonds, Corporate Performance, and Corporate Social Responsibility. Sustainability, 11(23), 27.

doi:https://doi.org/10.3390/su11236881 